\title{
GÊNESE, FUNÇÃO E COMPREENSÁO DOS NOVOS DIREITOS PRIVADOS
}

\author{
GENESIS, FUNCTION AND UNDERSTANDING OF NEW RIGHTS IN \\ PRIVATE LAW
}

\author{
Roberto Henrique Porto Nogueira ${ }^{\mathrm{I}}$ \\ Iara Antunes de Souza ${ }^{\mathrm{II}}$ \\ Leila Bitencourt Reis da Silva ${ }^{\text {III }}$
}

${ }^{\mathrm{I}}$ Universidade Federal de Ouro Preto,

Resumo: $O$ presente trabalho tem o objetivo de revelar o Ouro Preto, MG, Brasil. Doutora em Direito Privado. E-mail: roberto. nogueira@ufop.edu.br

${ }^{\text {II } U n i v e r s i d a d e ~ F e d e r a l ~ d e ~ O u r o ~ P r e t o, ~}$ Outro Preto, MG, Brasil. Doutora em Direito Privado. E-mail: iara@ufop.edu.br

III Universidade Federal de Minas Gerais, papel do Direito Privado no contexto das transformaçóes sociais e da correlata busca pela justiça social e pela efetivação dos direitos fundamentais. A partir disso, traça um cenário geral sobre perspectivas teóricas para a compreensão dos novos direitos, em especial os novos direitos privados, cuja discussão é edificante de projetos plurais de dignidades, bem como de posições jurídicas negociais. A hipótese consiste na ideia de que o Direito Privado não fica alheio às reinvindicaçóes emergentes da dinâmica social. Utiliza-se da vertente teóricoBelo Horizonte, MG, Brasil. Doutoranda dogmática por meio do uso de dados coletados em fonte em Direito. E-mail: leilareis091@gmail. com

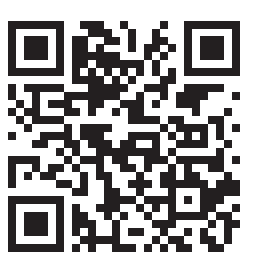

DOI: http://dx.doi.org/10.20912/rdc.v15i37.225

Recebido em: 18.202 .2020

Aceito em: 03.08.2020 primária e secundária, bibliográfica e documentalmente. Ao final, é possível concluir que os novos direitos são caracterizados e voltados à promoçáo do desocultamento de situações sociais não tratadas adequadamente pelo Direito Privado. Destaca-se também a concepção de novos direitos que não tem relação com o aspecto meramente cronológico, visto que a marca diferencial dos novos direitos é a sua relação com uma leitura que tem como premissa a admissão do pluralismo epistemológico.

Palavras-chave: Direito Privado. Pluralismo epistemológico. Novos Direitos. Desenvolvimento humano.

Abstract: This paper aims to reveal the role of Private Law in the context of social transformations and the related seek for social justice and for the concretization of fundamental rights. From this, a general scenario is outlined on theoretical perspectives for the understanding of new rights, especially in Private Law, in order to present a point of view that promotes plural projects of dignities and legal negotiating positions. The hypothesis consists in the idea that Private Law is not oblivious to the claims arising from the social dynamics. It uses the theoretical-dogmatic approach through the use of data collected in primary and secondary sources, bibliographically and documentally. In the end, it is possible to conclude that new rights are characterized and aimed at promoting the unveiling of social situations not adequately addressed by 
Private Law. Also noteworthy is the conception of new rights that has no relation to the merely chronological aspect, since the differential mark of new rights is their relationship with a reading that has as its premise the admission of epistemological pluralism.

Keywords: Private Law. Epistemological pluralism. New Rights. Human development.

\section{Introdução}

Parece inadmissível que o Direito Privado enquanto sistema permaneça alheio ao fenômeno do personalismo ético, dos direitos e garantias fundamentais, da necessária relação entre autonomia privada e autonomia pública, do fundamento do pluralismo político para a concreção do Estado Democrático de Direito e do objetivo fundamental de construção de uma sociedade livre, justa e solidária. Problematizar o papel do Direito Privado na atualidade para a consecução da justiça social parece imprescindível diante de sua tradição de clausura em face dos pressupostos constitucionalmente compartilhados.

Do mesmo modo, os processos interpretativos transformam-se para tornar possível o uso de novas perspectivas teóricas determinadas pela transdisciplinariedade. As instituições, por sua vez, são impactadas e chamadas a conformarem-se à realidade, que, assim como o Direito, passam a ser descritas e construídas a partir do pluralismo epistemológico que é pressuposto para a promoção da representaçáo política e da elaboração dos projetos plurais de dignidades.

No campo das políticas públicas, a flexibilização ou condicionamento das posturas, dos espaços, das prerrogativas e dos direitos a uma perspectiva distributiva de justiça social parece mais adequada. Vale indagar, lado outro, se os processos de revisitação do Direito Privado são também influenciados a contribuírem, em alguma medida, para essas finalidades que são tão evidentemente assumidas, especialmente a partir da Constituição da República de 1988.

A posição, talvez irrefletida, que a tradição do ensino jurídico pode assumir é a de que o Direito Privado se volta ao regime jurídico das relaçóes havidas entre particulares, na medida de suas autonomias privadas. Ainda nessa ótica, o Direito Privado pode referirse a posiçóes jurídicas negociais ou existenciais, essas últimas próprias dos direitos de personalidade articulados nos processos livres de autodeterminação social e identitária. Sistematicamente, costuma-se dizer que o Direito Privado é campo das relaçôes jurídicas paritárias entre pessoas naturais ou empresárias, podendo, no caso de relaçóes de consumo, articular mecanismos pontuais e bem definidos para o reequilíbrio dessas relações não paritárias (assim tidas, quase sempre, por presunção). A racionalidade que organiza esse panorama jurídico é essencialmente aquele ligado à noção de justiça comutativa. 
Ora, se a distributividade e a alocatividade de limites ao exercício de direitos ficam, prevalentemente, relegadas às justiças buscadas pelo Direito Público, nada ou muito pouco teria o Direito Privado a contribuir para as metas inicialmente apontadas. Tudo isso sugere que o Direito Privado apenas pode contemplar novos direitos oriundos do processo legislativo por excelência, náo podendo cunhar tais novos direitos em decorrência de reivindicaçóes ou carecimentos socialmente imanentes.

Ocorre que o Direito não fica alheio às reivindicações por novos direitos. Temas como a obrigaçáo dos planos de saúde de custear a criopreservação de embriōes de paciente que se encontra em quimioterapia, ${ }^{1}$ a possibilidade de redução ou suspensão da cobrança do aluguel do locatário que tem comprometimento de faturamento no cenário da pandemia de COVID-19 e hipóteses em que cogita a inaplicabilidade da ação de despejo nesse mesmo contexto são algumas das recentes situações em que o Direito Privado foi chamado a rever seus institutos face à demandas sociais. ${ }^{2}$

Resta refletir, portanto, se o Direito Privado é lócus viável para a gênese de novos direitos, ainda que o isso possa contrastar, eventualmente, com a tradicional lógica interpretativa de suas instituiçóes.

Por essa razão, objetiva-se esboçar a noção de novos direitos, de modo que, em suas inter-relaçóes, seja possível lançar luzes para o surgimento de novos direitos privados que consideram tais reivindicaçóes sociais. Apesar de os desafios serem muitos e de provocarem as mais variadas circunscriçóes do Direito Privado, direitos em concreto e julgados exemplificativos não são tratadas no presente estudo, face à opçáo de enfoque na gênese, na finalidade e na compreensão conceitual teórica sobre os novos direitos privados.

Nesse cenário, a vertente metodológica de maior relevo é a teórico-dogmática, eis que, a partir do sistema jurídico posto, pretende, pela via da coleta de dados em fonte bibliográfica e documental, promover, de modo argumentativo, o possível desenho de novos direitos privados.

O trabalho tem sua relevância evidente, devido à necessidade de revisitar algumas premissas de Direito Privado em razão de sua relaçáo com direitos e garantias fundamentais.

1 BRASIL. Superior Tribunal de Justiça. Recurso Especial 1.815.796. Relator: Paulo de Tarso Sanseverino - Terceira Turma. Diário de Justiça, Brasília, 21 jul. 2020. Disponível em: https://ww2. stj.jus.br/processo/revista $/$ documento $/$ mediado/? componente=ATC\&sequencial $=108444743 \& \mathrm{num}_{-}$ registro=201901504401\&data=20200609\&tipo=91\&formato=PDF. Acesso em: 23 jul. 2020.

2 BRASIL. Senado Federal. Projeto de Lei 1.179/2020. Dispõe sobre o Regime Jurídico Emergencial e Transitório das relaçóes jurídicas de Direito Privado (RJET) no período da pandemia do Coronavírus (Covid-19). Disponível em: http:// www.camara.gov.br/proposicoesWeb/fichadetramitacao?idProposicao=508884. Acesso em: 23 jul. 2020. O projeto sofreu alteraçôes até a sua aprovação. Vide: BRASIL. Lei Federal no 14.010, de 10 de junho de 2020. Diário Oficial da União, Brasília, 12 jun. 2020. Disponível em: http://www.planalto.gov.br/ccivil_03/_ato2019-2022/2020/lei/L14010.htm. Acesso em: 23 jul. 2020. 
Por fim, cabe a advertência de que o presente ensaio relata a percepçáo particular de seus autores sobre novos direitos havida no cenário da Pós-Graduação em Direito da Universidade Federal de Ouro Preto. Logo, se são intrínsecas, contínuas e recíprocas transformaçóes e influências sofridas por e entre o Direito e a sociedade, é bem verdade que, quando da publicação da discussão proposta, tais noçóes hão de estar, em alguma medida, superadas. Isso, entretanto, não representa comprometimento do argumento, mas sim uma inconsistência própria do pluralismo epistemológico que pauta o debate e que lhe é fértil, em termos sistemáticos, institucionais e interpretativos.

\section{Novos Direitos e Novos Direitos Privados}

A atualidade é marcada por uma perspectiva globalizante ou globalizada, na qual se destaca, comumente, a redução das distâncias existentes entre localidades e a fluência da forma ágil com que as informações são trocadas ao redor do mundo. Nesse cenário, certos sujeitos libertam-se, tornando-se emancipados das restriçôes territoriais e possuidores de um novo poder. Polarizados, do outro lado, localidades têm reduzidos os seus significados, de modo que às pessoas que têm pouca chance de locomoção resta observar o movimento, sob seus pés, dos lócus onde habitam. ${ }^{3}$

A expansão de um mercado mundial gera alto impacto não só no estilo de vida, mas também nas identidades e na cultura em geral, cuja diversidade é dissolvida face à crescente universalizaçáo de símbolos culturais, cada vez mais uniformizados. Vale dizer, a visão utópica de que o mundo globalizado é um mundo cosmopolita e pluralista parece falaciosa. Ao que se apresenta nesse panorama, o "ser" passa a estar diretamente ligado ao poder de compra e, por isso, os que náo podem comprar são excluídos, o que torna cada vez mais evidente a existência de um intenso aparthaid social. ${ }^{4}$

Dessa forma, sob a alcunha de "globalização", cabe muito mais do que o fenômeno de expansão de empresas transnacionais. Essa ideia alberga, assim, também o processo por meio do qual certa entidade local consegue se estender no resto do mundo, de maneira a ocupar e a transformar espaços culturais menos afetos a essa dinâmica expansionista. A partir disso, mostra-se mais adequado admitir a existência de globalizaçóes, haja vista que essa narrativa pode ser construída a partir da posiçáo do expansor - o que consegue impor o seu localismo - ou daquele que vê suas raízes locais distorcidas. Nota-se que, nos últimos tempos, os discursos têm sido construídos a partir do olhar do vencedor do processo de expansão global. ${ }^{5}$

3 BAUMAN, Zygmunt. Globalização: as consequências humanas. Rio de Janeiro: Zahar, 1999, p. 19.

4 BECK, Ulrich; CARONE, André. O que é a globalização? Equívocos do globalismo respostas à globalização. São Paulo: Paz e Terra, 1999, p. 85.86.

5 SANTOS, Boaventura de Sousa. Por uma concepção multicultural de direitos humanos. Lua Nova: Revista de Cultura e Política, n. 39, São Paulo, p. 106-124, 1997. Disponível em: http://www.scielo.br/pdf/ln/n39/a07n39.pdf. Acesso em: 10 set. 2019, p. 110. 
Boaventura de Sousa Santos qualifica o pensamento moderno ocidental como abissal. Para ele, o pensamento abissal pode ser percebido como uma sistemática baseada na divisão em que, de um lado, estão os sujeitos que são visíveis e dotados de existência, e, do outro, os invisíveis, para os quais somente resta o não existir. Essa divisão é marcada pela linha abissal. A origem desses opostos remonta ao período colonial em que as metrópoles empreendiam a dominação das colônias. Nessas bases, instala-se o pensamento abissal, cujo fundamento é o pensamento hegemônico e universal que promove a subalternização de certos sujeitos. ${ }^{6}$

Essa visão hegemônica tem efeitos em várias áreas do conhecimento, dentre elas as ciências sociais, visto que se estabelece o consenso da naturalizaçáo das relaçóes sociais, em que os valores das sociedades chamadas modernas são tidos como tendência natural, e, por isso, os únicos possíveis, definindo um contexto em que não se cogita o desenvolvimento de outros modos de vida. ${ }^{7}$

Diante desse cenário, é proposta a construção do pensamento pós-abissal, cuja proposta central é de que a exclusão gerada pela linha abissal somente pode ser eliminada se for possível reconhecer as inúmeras formas de afastamento produzida em conjunto, bem como se for possível empreender a busca pela emancipação dos oprimidos. ${ }^{8}$

O pensamento pós-abissal propõe, assim, uma nova perspectiva epistemológica, em que aqueles que ficam invisíveis do outro lado da linha abissal passam a produzir saberes conforme a sua realidade. Deixa-se de lado, igualmente, a unidade de pensamento posta pela epistemologia hegemônica, em que apenas uma forma de saber é considerada, e parte-se para premissa de que todas as formas de saber advindas de diferentes realidades sobre determinada temática devem coexistir. ${ }^{9}$

Essa visão que revela sujeitos costumeiramente desconsiderados, denominada desocultamento, concretiza o pluralismo epistemológico. Nessa perspectiva, o termo 'epistemologia' passa a ser compreendido de forma diferente da conceituação clássica, em que é considerada como uma disciplina filosófica que tem como objetivo apontar e analisar os princípios do conhecimento e seus fundamentos - que são entendidos como signos fortes, imóveis, únicos. Logo, o pluralismo decorre da admissão de múltiplas formas de saber, em que se propóe compreender o termo epistemologia em duas dimensões: a

6 SANTOS, Boaventura de Sousa. Para além do pensamento abissal: das linhas globais a uma ecologia de saberes. In: Novos estudos-CEBRAP, n. 79, p. 71-94, 2007. Disponível em: http://www.scielo.br/pdf/nec/n79/04.pdf. Acesso em: 22 jul. 2019, p. $72-73$.

7 LANDER, Edgardo. Ciências sociais: saberes coloniais e eurocêntricos. In: Lander, Edgardo (Org.). A colonialidade do saber: eurocentrismo e ciências sociais. Buenos Aires: Conselho Latino-americano de Ciências Sociais (CLACSO), 2005, p. 08-23, p. 08.

8 SANTOS, Boaventura de Sousa. Para além do pensamento abissal: das linhas globais a uma ecologia de saberes. In: Novos estudos-CEBRAP, n. 79, p. 71-94, 2007. Disponível em: http://www.scielo.br/pdf/nec/n79/04.pdf. Acesso em: 22 jul. 2019, p. 84 .

9 SANTOS, Boaventura de Sousa. Para além do pensamento abissal: das linhas globais a uma ecologia de saberes. In: Novos estudos-CEBRAP, n. 79, p. 71-94, 2007. Disponível em: http://www.scielo.br/pdf/nec/n79/04.pdf. Acesso em: 22 jul. 2019, p. $85-87$. 
descritiva - baseada em análises das várias práticas sociais geradoras de conhecimento - e a normativa, em que esse exame é utilizado para melhorar essas práticas, conforme as peculiaridades do meio cultural em que estiver inserida. Tem-se, assim, que não há uma prática certa, mas sim múltiplas práticas adequadas às capacidades cognitivas e açóes de seus agentes. ${ }^{10}$

Dentro da lógica do pluralismo, há de se cogitar a opçáo decolonial, por meio da qual se busca compreender saberes fora da lógica dos conhecimentos gerados a partir de

[...] fundamentos genuínos de conceitos ocidentais e da acumulação de conhecimento. Por abandono epistêmico não quer dizer abandono ou ignorância do que já foi institucionalizado por todo o planeta. Pretende-se substituir a geo-e a politica do Estado de conhecimento de seu fundamento na história imperial do Ocidente nos últimos séculos pela geo-politica e a política do Estado de pessoas, línguas, religióes, conceitos políticos e econômicos, subjetividades, etc, que foram racializadas (ou seja, sua óbvia humanidade foi negada). (Grifou-se). ${ }^{11}$

A partir de uma opção decolonial, de um pensamento pós-abissal e de uma concepção de epistemologia que se dedica às múltiplas formas de saberes, abre-se campo aos novos direitos. Trata-se de teia teórico-discursiva necessária para o reconhecimento de direitos por meio de releituras de institutos tradicionais, bem como para a compreensão dos sujeitos invisibilizados e ocultados em suas múltiplas dimensóes: pública, privada, pessoal, coletiva, ambiental, histórica, cultural, corporativa e patrimonial, face a discriminaçóes históricas e a novos ocultamentos ocasionados por processos de desenvolvimento social.

Os novos direitos representam, assim, a multiplicação da previsão de direitos em razão de uma relação de interdependência em que "o reconhecimento de novos direitos de (onde 'de' indica o sujeito) implica quase sempre o aumento de direitos a (onde 'a' indica o objeto)". ${ }^{12}$

Apesar de fenômenos de dominação serem bastante antigos, sendo marcados, na modernidade, pelas expansóes marítimas, é bem verdade que também se registraram resistências de subjugados pelo poder. A luta por novos direitos já encontrou como adversários o poder religioso, o poder político e o poder econômico. Hodiernamente, os novos direitos enfrentam, também, o obstáculo do poder das conquistas da ciência e de quem está apto a usá-lo. Despontam-se carecimentos. Diante desse intenso e irreversível processo, percebe-se não se tratar simplesmente de uma transformação tecnológica, mas sim tecnocrática do mundo. Como a ciência hoje é o poder, o domínio das técnicas

10 OLIVÉ, León. Por una auténtica interculturalidad basada em el reconocimiento de la pluralidad epistemológica. In: OLIVÉ, Leon et al (org.) Pluralismo Epistemológico. La Paz: Muela del Diablo Editores, 2009, p, 19-30, p. 26-28.

11 MIGNOLO, Walter D. Desobediência epistêmica: a opçáo decolonial e o significado de identidade em política. In: Cadernos de Letras da UFF - Dossiê: Literatura, língua e identidade, n. 34, p. 237-324, 2008. Disponível em: www.uff.br/ cadernosdeletrasuff/34/traducao.pdf. Acesso em: 18 ago. 2019, p. 289-290.

12 BOBBIO, Norberto. Era dos direitos. Rio de Janeiro: Elsevier, 2004, p. 33. 
científicas entra no rol dos meios que podem ser utilizados pelo ser humano para dominar uns aos outros. ${ }^{13}$

Em relação à compreensão dos novos direitos, tem-se que os "Direitos Humanos" estão contidos nos "Novos Direitos", pois, adotando-se uma concepção operacional de Direitos Humanos que tem como núcleo conceitual a concretização à proteção à dignidade humana, é improvável imaginar o surgimento de novos sujeitos que violem essa dignidade. Ainda dentro dessa perspectiva, considera-se que a tutela de bens pode recair sobre quaisquer elementos passíveis de serem juridicamente resguardados. ${ }^{14}$

Menciona-se também a necessidade de “instrumentos de efetivação", que constituem uma série de açóes e instrumentos de base processual/procedimental que têm como principal finalidade o reconhecimento e a materialização de um novo direito. Cabe a alusão, igualmente, à ligação entre os novos direitos e as inovações tecnológicas tomadas aqui como resultados que advêm de operaçóes submetidas a rígidos padróes de $\mathrm{P}$ \& D (Pesquisa e Desenvolvimento), numa estreita relação homem/pesquisa/“máquina” e as inovaçóes não tecnológicas, que também podem provocar/integrar relaçóes jurídicas que envolvam novos direitos. ${ }^{15}$

\subsection{Novos Direitos Privados e as "geraçôes de direitos"}

O estudo dos novos direitos também se relaciona às "geraçóes" de direitos, as quais, ainda que passíveis de crítica, auxiliam a compreensão desses novos modelos. Afinal, as geraçóes explicitam as demandas emergentes da sociedade em diferentes momentos da história. Assim, por meio de critérios como o conteúdo, titularidade, efetivação e sistematização, elencam-se 5 (cinco) "geraçôes" do Direito. ${ }^{16}$

Se os direitos de primeira geração têm como objetivo a promoção de direitos negativos individuais que garantam, em especial, a liberdade, a igualdade e a propriedade contra o Estado, os direitos da segunda geração são marcados pela busca da concretização de direitos sociais, econômicos e culturais fincados em um sentido de igualdade com aspecto positivo, que não se destinam a serem opostos contra o Estado, mas, sim, que pelo poder público sejam garantidos e concedidos a todos os indivíduos. ${ }^{17}$

13 BOBBIO, Norberto. Era dos direitos. Rio de Janeiro: Elsevier, 2004, p. 96.

14 PASOLD, César Luiz. Novos direitos: conceitos operacionais de cinco categorias que lhes são conexas. Seqüência: Estudos Jurídicos e Políticos, Florianópolis, p. 225-236, jan. 2005. Disponível em: https://periodicos.ufsc.br/index.php/sequencia/ article/view/15192. Acesso em: 12 ago. 2019, passim.

15 PASOLD, César Luiz. Novos direitos: conceitos operacionais de cinco categorias que lhes são conexas. Seqüência: Estudos Jurídicos e Políticos, Florianópolis, p. 225-236, jan. 2005. Disponível em: https://periodicos.ufsc.br/index.php/sequencia/ article/view/15192. Acesso em: 12 ago. 2019, passim.

16 WOLKMER, Antonio Carlos. Introdução aos Fundamentos de uma Teoria Geral dos 'Novos' Direitos. Revista Jurídica Unicuritiba, v. 2, n. 31, p. 121-148, 2013. Disponível em: http://revista.unicuritiba.edu.br/index.php/RevJur/article/ view/593/454. Acesso em: 12 ago. 2019, p. 125.

17 WOLKMER, Antonio Carlos. Introdução aos Fundamentos de uma Teoria Geral dos 'Novos' Direitos. Revista Jurídica Unicuritiba, v. 2, n. 31, p. 121-148, 2013. Disponível em: http://revista.unicuritiba.edu.br/index.php/RevJur/article/ view/593/454. Acesso em: 12 ago. 2019, p. 126-128. 
Os direitos de terceira dimensão destacam-se por ultrapassar a individualidade. Sáo os direitos coletivos e difusos, direitos de solidariedade. Tais direitos não têm como titular a pessoa enquanto indivíduo, pois se destinam a certos grupos de pessoas. No que tange à quarta geração, o que a caracteriza é a vinculação à biotecnologia, à bioética e à regulação da engenharia genética. Relacionam-se, assim, com uma complexa e interdisciplinar rede de agentes, como médicos, juristas, biólogos, filósofos, teólogos, psicólogos, sociólogos, humanistas e profissionais da saúde em geral. A quinta geração tem ligaçáo direta com a regulamentação da ciência informática e tudo que a permeia, como o direito à privacidade, à informação e à autodeterminação informativa, e ao controle dos dados e dos crimes via rede. ${ }^{18}$

A análise das geraçóes permite realçar um importante aspecto dos novos direitos como resultados de necessidades históricas dentro de uma relatividade e de uma pluralidade regida pelos agentes envolvidos. Essa divisão em geraçóes ou dimensóes não é estanque nem definida por meio de critérios exclusivamente cronológicos, pois os tempos de seus surgimentos e verificaçóes ocorrem de forma entrelaçada e sobreposta pois serve, sim, para fins didático-explicativos e compreensivos do momento histórico de sua expansão ou reconhecimento, parte da premissa de que, no que tange à qualidade de vida, bem-estar e materialidade social, não se podem excluir as questóes individuais, políticas, religiosas, psicológicas, biológicas e culturais. Assim, tendo em vista que as necessidades humanas são inesgotáveis e ilimitadas, os novos direitos estão em permanente construção. Nesse contexto, o "novo" nem sempre é permeado de novidade em seu conteúdo, mas pode ser considerado novo devido ao modo de sua obtençáo ou concretizaçáo, alheio às vias tradicionais. Enfim, as geraçóes evidenciam a maneira com a qual o processo histórico faz com que haja criaçáo ininterrupta dos "novos" direitos por meio de novas necessidades que moldem novos atores sociais. ${ }^{19}$

Os novos direitos são pertinentes, dessa forma, diretamente, ao cenário brasileiro, tendo em vista que, assim como a realidade latino-americana, possui uma série de sujeitos históricos emergentes que lutam ou aguardam por atenção jurídica às suas necessidades básicas, como alimentação, educação, saúde, saneamento, moradia, dentre tantas outras carências vividas. Assim, diante uma tradição histórica de exclusóes, de imposiçóes e carências, "as práticas emancipadoras insurgentes das novas identidades sociais são portadoras em potencial de novas e legítimas formas de fazer política, além de fonte alternativa e diferenciada de produção jurídica” ${ }^{20}$.

18 WOLKMER, Antonio Carlos. Introdução aos Fundamentos de uma Teoria Geral dos 'Novos' Direitos. Revista Jurídica Unicuritiba, v. 2, n. 31, p. 121-148, 2013. Disponível em: http://revista.unicuritiba.edu.br/index.php/RevJur/article/ view/593/454. Acesso em: 12 ago. 2019, p. 126-134.

19 WOLKMER, Antonio Carlos. Introdução aos Fundamentos de uma Teoria Geral dos 'Novos' Direitos. Revista Jurídica Unicuritiba, v. 2, n. 31, p. 121-148, 2013. Disponível em: http://revista.unicuritiba.edu.br/index.php/RevJur/article/ view/593/454. Acesso em: 12 ago. 2019, p. 136-137).

20 WOLKMER, Antonio Carlos. Mudanças de paradigmas, Pluralismo e Novos Direitos. Espaço Jurídico, v. 7, p. 87-96, 2006. Disponível em: https://editora.unoesc.edu.br/index.php/espacojuridico/article/view/8795. Acesso em: 12 ago. 2019, p. 93. 
Nesse sentido, novos direitos podem emergir, por exemplo, como reflexo da busca pelo repensar das teorias feministas e do papel da mulher conforme as peculiaridades dos países do Sul, pois "às mulheres latino-americanas cabe modular e filtrar as teorias feministas Norte-Globais, de maneira a tomar e retomar a autoria do discurso, do protagonismo e da própria elaboração do arsenal teórico a si aplicável". ${ }^{21}$ Novos direitos, também, podem representar novas epistemologias acerca da teoria das (in)capacidades, considerando a nova visão multidisciplinar e biopsicossocial acerca das pessoas com deficiência; de institutos tradicionais como a curatela e a interdição e, como antecedente, do próprio conceito de autonomia privada, como possibilidade de expressáo de vontade $) .22$

\subsection{Novos Direitos Privados e o Direito Achado na Rua}

Essa concepçáo de novos direitos possui alguma identificação com o movimento chamado Direito Achado na Rua, expressão cunhada por Roberto Lyra Filho, cujo objetivo é expressar uma concepção de Direito que é emergente e transformador "dos espaços públicos - a rua - onde se dá a formação de sociabilidades reinventadas que permitem abrir a consciência de novos sujeitos para uma cultura de cidadania e de participação democrática”. Essa expressão também remete à abordagem epistemológica organizada na Universidade de Brasília com o objetivo de capacitar assessorias jurídicas de movimentos sociais, bem como de buscar investigar espaços sociais no fito de compreender e inserir o sujeito coletivo dentro do sistema jurídico, para que essas práticas possam constituir novas categorias jurídicas. ${ }^{23}$

Em comum com os novos direitos, o Direito Achado na Rua tem a questão da emancipação dos invisibilizados, haja vista que parte da proposição de Direito que

[...] não poderá desprezar todos esses aspectos do processo histórico, em que o círculo da legalidade não coincide, sem mais, com o da legitimidade, como notava, entre outros, inclusive o grande jurista burguês Hermann Heller. Diríamos até que, se o Direito é reduzido à pura legalidade, já representa a dominação ilegítima, por força desta mesma suposta identidade; e este "Direito" passa, entấo, das normas estatais, castrado, morto e embalsamado, para o necrotério duma pseudociência, que os juristas conservadores, não à toa, chamam de "dogmática". Uma ciência verdadeira, entretanto, não pode fundar-se em "dogmas", que divinizam as normas do Estado, transformam essas práticas pseudocientíficas em tarefa de boys do imperialismo e da dominação e degradam a procura do saber numa ladainha de capangas inconscientes ou espertos.

21 FERREIRA, Paula Camila Veiga; NOGUEIRA, Roberto Henrique Pôrto. Teoria política feminista sul-global: perspectivas do feminismo transnacional para uma transposição epistemológica rumo à alteridade e à igualdade substancial. In: Revista de Gênero, Sexualidade e Direito, Maranhão, v. 3, n. 2, p. 22-42, Jul/Dez 2017, p. 38-39.

22 SOUZA, Iara Antunes de. Estatuto da Pessoa com Deficiência: Curatela e Saúde Mental. Belo Horizonte: D’Plácido Editora, 2016, passim.

23 SOUSA JÚNIOR, José Geraldo de. Direito como liberdade: o Direito Achado na Rua. Experiências populares emancipatórias de criação do Direito. 2008. 341f. Tese (Doutorado) - Universidade de Brasília, Programa de Pós-Graduação em Direito, Brasília. Disponível em: http://repositorio.unb.br/handle/10482/1401. Acesso em: 12 set. 2019, p. 14 e 193. 
[...] nosso objetivo é perguntar, no sentido mais amplo, o que é Direito (com ou sem leis), mas é preciso esclarecer, igualmente, que nada é, num sentido perfeito e acabado; que tudo é, sendo. Queremos dizer, com isto, que as coisas não obedecem a essências ideais, criadas por certos filósofos, como espécie de modelo fixo, um cabide metafísico, em que penduram a realidade dos fenômenos naturais e sociais. As coisas, ao contrário, formamse nestas próprias condiçóes de existência que prevalecem na Natureza e na Sociedade, onde ademais se mantêm num movimento constante e contínua transformação. E deste modo que elas se entrosam na totalidade dos objetos observáveis e das forças naturais e sociais, que os modelam e orientam a sua evolução. Cada fenômeno (fenômeno é, etimologicamente, coisa que surge) pode, então, revelar o seu fundamento e sentido, que só emerge em função daquela totalidade móvel. Isoladamente, cada um perde a significação própria e a conexão vital, assim como o órgão sem o organismo em que funciona, ou o homem, sem a sociedade, fora da qual ele não existe humanamente e regride na escala zoológica. (Grifou-se). ${ }^{24}$

O Direito Achado na Rua, portanto, também tem como base o pluralismo epistemológico, na medida em que, no âmbito das ciências jurídicas, leva em consideração a diversidade das manifestações informais, que se caracterizam por serem não estatais. ${ }^{25} \mathrm{O}$ Direito Achado na Rua, desse modo, não só concretiza novos direitos, como também se pauta por uma perspectiva mais ampla do desenvolvimento humano, ao considerar que o Direito "se faz no processo histórico de libertação enquanto desvenda precisamente os impedimentos da liberdade náo-lesiva aos demais. Nasce na rua, no clamor dos espoliados e oprimidos". ${ }^{26}$

Novos direitos podem, ainda, guardar intimidade com a noção de liberdade substantiva, considerada como meio para o desenvolvimento das capacidades das pessoas. ${ }^{27}$ Assim, ao partir da premissa de que cada pessoa é um fim em si mesmo, privilegia-se a promoção efetiva da liberdade, visto que isso possibilita que uma série de direitos pressupostos (capacidades) possa ser implementada e exercida em conformidade com as convicções mais particulares. ${ }^{28}$

Nessa perspectiva, o desafio de lidar com os novos direitos é atinente ao Direito Privado como um todo, tendo em vista a necessidade de seus institutos amoldarem-se às demandas sociais atuais para que possam ser instrumentos estratégicos de uma sociedade fraterna, plural e livre de preconceitos. É dessa forma que a vontade e a liberdade passam a ser cada vez mais revisitadas, o que permite o redesenho de sistemas específicos que consigam tutelar e promover direitos aos sujeitos e grupos menos favorecidos, sem lhes

24 LYRA FILHO, Roberto. O que é direito. São Paulo: Brasiliense, 1982, p. 3-6.

25 OLIVEIRA, Assis da Costa. O Direito achado na rua: concepção e prática, de José Geraldo de Sousa Júnior. InSURgência: revista de direitos e movimentos sociais, Brasília, p. 562-568, v. 1, n. 2, dez. 2015. Disponível em: http://webcache. googleusercontent.com/search?q=cache:hYMXybf9cTQJ:periodicos.unb.br/index.php/insurgencia/article/ download/20069/14259+\&cd=1\&hl=pt-BR\&ct=clnk\&gl=br . Acesso em: 12 ago. 2019, p. 565.

26 LYRA FILHO, Roberto. O que é direito. São Paulo: Brasiliense, 1982, p. 312.

27 SEN, Amartya Kumar. Desenvolvimento como liberdade. São Paulo: Companhia das Letras, 2000, p. 26.

28 NUSSBAUM, Marta C. Creating capabilities: the human development approach. Cambridge: Belknap Press of Harvard University, 2011, p. 18-19. 
retirar a autodeterminação, bem como em conformidade com os seus próprios contextos e peculiaridades. ${ }^{29}$

Assim, todas as relaçóes jurídicas, inclusive as cunho privado, vêm recebendo forte influência de premissas que adentram no ordenamento, como, por exemplo, a releitura do contrato em razão dos ditames da boa-fé objetiva, que atingem o conteúdo relacional das mais diversificadas maneiras. Discussóes sobre igualdade substancial, que, neste estudo, relaciona-se à ideia de diversidade, ${ }^{30}$ também passam a ser inseridas nas questóes atinentes à comutatividade contratual e à distribuição equitativa de riscos em um contrato, o que resulta na crescente busca pelo equilíbrio econômico e pelo tratamento paritário na relação contratual. A função social passa a ser pauta de discussóes da propriedade e do contrato, dando nova roupagem à autonomia privada. ${ }^{31}$

Novos direitos, assim, tendem a resultar do processo de confrontamento do direito com transformaçóes sociais reveladoras de ocultamentos ou invisibilidades, num movimento de flexibilização procedimental e, residualmente, conteudístico. Dessa forma, pode-se afirmar que os novos direitos náo necessariamente são direitos novos. Novos direitos são aqueles relacionados a uma perspectiva plural e mutável de Direito que compreende o sistema jurídico para além de mero perpetuador de legitimidades e modelos cristalizados.

Os novos direitos decorrem da concepção de Direito que é, sim, disruptiva, pois possibilita que novas posturas interpretativas sejam adotadas, por meio de epistemologias adequadas aos fundamentos de validade jurídicos intrassistêmicos (ligados aos direitos e garantias fundamentais), que tendem a não perder de vista, ainda, o horizonte da experiência humana construída de modo compartilhado e transversal.

Significa dizer que novos direitos parecem ser ressignificaçóes de institutos jurídicos existentes ou frutos de carecimentos e espaços merecedores de tutela, evidenciados ininterruptamente tanto em panoramas de novos cenários ou possibilidades sociais (inclusive tecnológicas) quanto em lutas ou disputas por prerrogativas, titularidades, posiçóes, reconhecimentos e/ou representatividades, possivelmente oriundos de perspectivas ligadas aos Direitos Humanos, mas sempre atrelados a uma teia recursiva que admita o pluralismo epistemológico aplicado aos saberes diversos e contextualizados,

29 FIUZA, César Augusto de Castro; NOGUEIRA, Roberto Henrique Pôrto; SILVA, Leila Bitencourt Reis da. Vulnerabilidade como parâmetro interpretativo necessário à vedação do conhecimento, de ofício, da abusividade de cláusulas em contratos bancários de consumo. In: SÁ, Maria de Fátima Freire; NOGUEIRA, Roberto Henrique Pôrto; SCHETTINI, Beatriz. (Org.). Novos direitos privados. Belo Horizonte: Arraes, 2016, p. 157-169, p. 163.

30 BAHIA, Alexandre Gustavo Melo Franco. Igualdade: 3 dimensôes, 3 desafios. CLÈVE, Clèmerson Merlin; FREIRE, Alexandre (Coord.). Direitos fundamentais e jusridição constitucional: análise, crítica e contribuiçōes. São Paulo: Editora Revista dos Tribunais, 2014. p. 73-98.

31 FIUZA, César. NOGUEIRA, Roberto Henrique Pôrto. Relações Jurídicas Interempresariais e a Artificialidade da Atribuição da Natureza Consumerista em Razão da Vulnerabilidade. In: BRAGA NETTO, Felipe Peixoto; SILVA, Michael César (Org.). Direito Privado e Contemporaneidade: Desafios e perspectivas do direito privado no século XXI. Belo Horizonte: D’Plácido, 2014, p. 243-263, p. 250-251. 
numa inter-relação indissociável entre culturas, identidades e experiências. Essa dinâmica considera a possibilidade de ajustes procedimentais e, residualmente, substanciais. $\mathrm{O}$ processo de gênese e/ou revelação de novos direitos náo se confunde com o surgimento de novas legislaçóes ou de novas figuras jurídicas que sejam elaboradas de modo alheio a esse delineamento, haja vista que, nesse caso, tendem a ser meros direitos novos implementados por velhas visóes, pouco plurais e prevalentemente hegemônicas, que nada mais representam que a explícita continuidade ou intensificação de posturas expansionistas de direitos de grupos e de posiçóes historicamente privilegiados.

\section{Notas finais sobre o (novo) Direito Privado}

As aptidóes e as condiçóes para exercício efetivo de capacidades humanas devem ser privilegiadas pelo Direito, na medida dos espaços de ressalva às racionalidades comutativas próprias do Direito Privado. ${ }^{32}$

Se os novos direitos são possíveis repercussóes da dinâmica de interação do Direito com transformaçóes sociais reveladoras de ocultamentos ou de invisibilidades, novos modelos jurídicos náo se formatam, fundamentalmente, como direitos cronologicamente novos. Novos direitos são, a rigor, direitos pertinentes a uma perspectiva plural, diversa e mutável do ordenamento jurídico que admitem a mutação e a rejeição de legitimidades e modelos consolidados. Logo, novos direitos surgem a partir do panorama do pluralismo epistemológico, para um saber jurídico contextualizado, integrado e aberto a culturas, identidades e experiências.

Vale dizer, ressignificaçóes de institutos jurídicos existentes ou frutos de demandas sociais, regimes jurídicos desenhados para adequação a novas tecnologias e circunstâncias correlatas, reações aos influxos de disputas e de consecução de direitos humanos são algumas das possibilidades arquetípicas atreladas aos novos direitos.

A questão que subsiste é o reconhecimento desses espaços propícios ao intuito distributivo e alocativo de limites às liberdades individuais.

Pode o Direito Privado enclausurar-se, de modo a ignorar aspectos ensejadores de novos direitos?

Como já dito outrora, a provocação para amoldar, interiorizar e articular novos direitos é também finalidade própria do Direito Privado. Os cenários sociais deflagradores da necessidade de implementação de programas constitucionais promovem a revelação, também para o Direito Privado, de estratégias técnico-jurídicas aptas à colaboração para a concreção de uma sociedade que, além de prezar pela liberdade e pela igualdade, admita o compromisso da solidariedade.

32 DRESCH, Rafael de Freitas Valle. Fundamentos do direito privado: uma teoria da justiça e da dignidade humana. São Paulo Atlas 2013. 
Sistemicamente, o Direito Privado já demonstra sua aptidão para tutelar posiçóes vulneráveis. Trata-se de imposição que decorre dos Direitos e Garantias Fundamentais. O (novo) Direito Privado atua no sentido de enfrentamento ou da tutela de desafios havidos em contextos nos quais a racionalidade meramente comutativa deve ceder espaço, excepcionalmente, a uma perspectiva de justiça distributiva, de modo a emanar efeitos de uma adequada abordagem desse fenômeno transversal.

\section{Referências}

BRASIL. Lei Federal no 14.010, de 10 de junho de 2020. Diário Oficial da União, Brasília, 12 jun. 2020. Disponível em: http://www.planalto.gov.br/ccivil_03/_ato20192022/2020/lei/L14010.htm. Acesso em: 23 jul. 2020.

BRASIL. Senado Federal. Projeto de Lei 1.179/2020. Dispóe sobre o Regime Jurídico Emergencial e Transitório das relaçóes jurídicas de Direito Privado (RJET) no período da pandemia do Coronavírus (Covid-19). Disponível em: http://www.camara.gov.br/ proposicoes Web/fichadetramitacao?idProposicao=508884. Acesso em: 23 jul. 2020.

BRASIL. Superior Tribunal de Justiça. Recurso Especial 1.815.796. Relator: Paulo de Tarso Sanseverino - Terceira Turma. Diário de Justiça, Brasília, 21 jul. 2020. Disponível em: https://ww2.stj.jus.br/processo/revista/ documento $/$ mediado/?componente=ATC\&sequencial=108444743\&num_ registro $=201901504401 \&$ data $=20200609 \&$ tipo $=91 \&$ formato $=$ PDF. Acesso em: 23 jul. 2020.

BAHIA, Alexandre Gustavo Melo Franco. Igualdade: 3 dimensões, 3 desafios. CLÈVE, Clèmerson Merlin; FREIRE, Alexandre (Coord.). Direitos fundamentais e jusridição constitucional: análise, crítica e contribuiçóes. São Paulo: Editora Revista dos Tribunais, 2014. p. 73-98.

BAUMAN, Zygmunt. Globalização: as consequências humanas. Rio de Janeiro: Zahar, 1999.

BECK, Ulrich; CARONE, André. O que é a globalização? Equívocos do globalismo respostas à globalização. São Paulo: Paz e Terra, 1999.

BOBBIO, Norberto. Era dos direitos. Rio de Janeiro: Elsevier, 2004.

DRESCH, Rafael de Freitas Valle. Fundamentos do direito privado: uma teoria da justiça e da dignidade humana. São Paulo Atlas 2013.

FELIPE, Sônia T. Racionalidade e vulnerabilidade: elementos para a redefinição da sujeição moral: Veritas (Porto Alegre), v. 52, n. 1, 2007. Disponível em: http:// 
evistaseletronicas.pucrs.br/ojs/index.php/veritas/article/view/1868. Acesso em: 26 fev. 2019.

FERREIRA, Paula Camila Veiga; NOGUEIRA, Roberto Henrique Pôrto. Teoria política feminista sul-global: perspectivas do feminismo transnacional para uma transposição epistemológica rumo à alteridade e à igualdade substancial. In: Revista de Gênero, Sexualidade e Direito, Maranhão, v. 3, n. 2, p. 22-42, Jul/Dez 2017.

FIUZA, César Augusto de Castro; NOGUEIRA, Roberto Henrique Pôrto; SILVA, Leila Bitencourt Reis da. Vulnerabilidade como parâmetro interpretativo necessário à vedação do conhecimento, de ofício, da abusividade de cláusulas em contratos bancários de consumo. In: SÁ, Maria de Fátima Freire; NOGUEIRA, Roberto Henrique Pôrto; SCHETTINI, Beatriz. (Org.). Novos direitos privados. Belo Horizonte: Arraes, 2016, p. 157-169.

FIUZA, César. NOGUEIRA, Roberto Henrique Pôrto. Relações Jurídicas Interempresariais e a Artificialidade da Atribuição da Natureza Consumerista em Razão da Vulnerabilidade. In: BRAGA NETTO, Felipe Peixoto; SILVA, Michael César (Org.). Direito Privado e Contemporaneidade: Desafios e perspectivas do direito privado no século XXI. Belo Horizonte: D’Plácido, 2014, p. 243-263.

LANDER, Edgardo. Ciências sociais: saberes coloniais e eurocêntricos. In: Lander, Edgardo (Org.). A colonialidade do saber: eurocentrismo e ciências sociais. Buenos Aires: Conselho Latino-americano de Ciências Sociais (CLACSO), 2005, p. 08-23.

LYRA FILHO, Roberto. Desordem e Processo: um prefácio explicativo. In: LYRA, Doreodó Araújo (org). Desordem e Processo. Porto Alegre: Sergio Antônio Fabris Editor, 1986, p. 263-333.

LYRA FILHO, Roberto. O que é direito. São Paulo: Brasiliense, 1982.

MIGNOLO, Walter D. Desobediência epistêmica: a opção decolonial e o significado de identidade em política. In: Cadernos de Letras da UFF- Dossiê: Literatura, língua e identidade, n. 34, p. 237-324, 2008. Disponível em: www.uff.br/ cadernosdeletrasuff/34/traducao.pdf. Acesso em: 18 ago. 2019.

NUSSBAUM, Marta C. Creating capabilities: the human development approach. Cambridge: Belknap Press of Harvard University, 2011.

OLIVÉ, León. Por una auténtica interculturalidad basada em el reconocimiento de la pluralidad epistemológica. In: OLIVÉ, Leon et al (org.) Pluralismo Epistemológico. La Paz: Muela del Diablo Editores, 2009, p, 19-30.

OLIVEIRA, Assis da Costa. O Direito achado na rua: concepção e prática, de José Geraldo de Sousa Júnior. InSURgência: revista de direitos e movimentos sociais, Brasília, p. 562-568, v. 1, n. 2, dez. 2015. Disponível em: http://webcache. googleusercontent.com/search?q=cache:hYMXybf9cTQJ:periodicos.unb.br/index. 
$\mathrm{php} /$ insurgencia/article/download/20069/14259+\&cd=1\&hl=pt-BR\&ct=clnk\&gl=br . Acesso em: 12 ago. 2019.

PASOLD, César Luiz. Novos direitos: conceitos operacionais de cinco categorias que lhes sấo conexas. Seqüência: Estudos Jurídicos e Politicos, Florianópolis, p. 225-236, jan. 2005. Disponível em: https://periodicos.ufsc.br/index.php/sequencia/article/ view/15192. Acesso em: 12 ago. 2019.

SANTOS, Boaventura de Sousa. Para além do pensamento abissal: das linhas globais a uma ecologia de saberes. In: Novos estudos-CEBRAP, n. 79, p. 71-94, 2007. Disponível em: http://www.scielo.br/pdf/nec/n79/04.pdf. Acesso em: 22 jul. 2019.

SANTOS, Boaventura de Sousa. Por uma concepção multicultural de direitos humanos. Lua Nova: Revista de Cultura e Política, n. 39, São Paulo, p. 106-124, 1997. Disponível em: http://www.scielo.br/pdf/ln/n39/a07n39.pdf. Acesso em: 10 set. 2019.

SEN, Amartya Kumar. Desenvolvimento como liberdade. São Paulo: Companhia das Letras, 2000.

SOUZA, Iara Antunes de. Estatuto da Pessoa com Deficiência: Curatela e Saúde Mental. Belo Horizonte: D’Plácido Editora, 2016.

SOUSA JÚNIOR, José Geraldo de. Direito como liberdade: o Direito Achado na Rua. Experiências populares emancipatórias de criação do Direito. 2008. 341f. Tese (Doutorado) - Universidade de Brasília, Programa de Pós-Graduação em Direito, Brasília. Disponível em: http://repositorio.unb.br/handle/10482/1401. Acesso em: 12 set. 2019.

WOLKMER, Antonio Carlos. Introdução aos Fundamentos de uma Teoria Geral dos 'Novos' Direitos. Revista Jurídica Unicuritiba, v. 2, n. 31, p. 121-148, 2013. Disponível em: http://revista.unicuritiba.edu.br/index.php/RevJur/article/view/593/454. Acesso em: 12 ago. 2019.

WOLKMER, Antonio Carlos. Mudanças de paradigmas, Pluralismo e Novos Direitos. Espaço Jurídico, v. 7, p. 87-96, 2006. Disponível em: https://editora.unoesc.edu.br/ index.php/espacojuridico/article/view/8795. Acesso em: 12 ago. 2019. 